\title{
Microstructural Evolution during Partial Melting and Semisolid Forming Behaviors of Two Hot-Extruded Magnesium-Rare Earth Alloys
}

\author{
Jian-Sheng Zhang, Jie Zhou, Yu-Feng Xia, Qian Li, Yao Tang, Yi Meng \\ College of Materials Science and Engineering, Chongqing University, Chongqing, China
}

\begin{abstract}
Reheating experiments and semisolid compression tests were conducted on two hot-extruded magnesiumrare earth (Mg-RE) alloys, Mg-8.20Gd-4.48Y-0.36Zr-3.34Zn and $\mathrm{Mg}-3.75 \mathrm{Gd}-5.15 \mathrm{Y}-0.75 \mathrm{Zr}-3.05 \mathrm{Zn}$ by using a multistage hot compression test machine. Dissolution of eutectic compounds, growth of grains, and partial melting took place during the reheating of these $\mathrm{Mg}$-RE alloys and resulted in spherical semisolid slurries at certain temperatures $\left(580{ }^{\circ} \mathrm{C}\right.$ for $\mathrm{Mg}-8.20 \mathrm{Gd}-4.48 \mathrm{Y}-3.34 \mathrm{Zn}-0.36 \mathrm{Zr}$, $560{ }^{\circ} \mathrm{C}$ for Mg-3.75Gd-5.15Y-0.75Zr-3.05Zn). Owing to the different alloying element contents of these two Mg-RE alloys, eutectic compounds with different morphologies were found inside them after reheating and rapid cooling processes. The forming characteristics of these two Mg-RE alloys in semisolid state were discussed based on the results of compression tests.
\end{abstract}

\section{Introduction}

Addition of $\mathrm{Zr}$ and rare earth (RE) elements was one of the most feasible precipitation strengthening methods for $\mathrm{Mg}$ alloys [1]. Compared with conventional $\mathrm{Mg}$ alloys, Mg-RE alloys exhibited more excellent high-temperature mechanical properties [2]. Thus, Mg-RE could be used to manufacture structural parts working in extreme environment [3]. However, casting was not an ideal forming process for Mg-RE alloys, because of the weaker mechanical properties of cast parts [4]. Moreover, the formalities of $\mathrm{Mg}-\mathrm{RE}$ alloys for traditional forging were not good enough to meet the requirement of near-shape forming [5].

Owing to the characteristic microstructure and forming behaviors of different phases in semisolid slurries, semisolid forming technology was considered as one of the idea forming technology to realize the nearshape forming of Mg-RE alloys [6]. The feasibility of semisolid forming in manufacturing of conventional $\mathrm{Mg}$ alloy parts was verified by in the past decade by researchers [7-9]. However, the research on semisolid forming of $\mathrm{Mg}-\mathrm{RE}$ alloys is quite limited. To establish a feasible strategy for semisolid forming of Mg-RE alloys, essential acknowledgements should be obtained and accumulated by basic experiments.

In this study, two hot-extruded Mg-RE alloys with different chemical compositions were selected as starting materials. A series of reheating-cooling experiments, semisolid compression tests were conducted in this study. On the basis of the experimental results, not only the microstructural evolution of those Mg-RE alloys during reheating, subsequent cooling, and semisolid forming, but also the semisolid forming behaviors of those alloys were investigated and discussed.

\section{Experiments}

In this study, Mg-8.20Gd-4.48Y-0.36Zr-3.34Zn and Mg$3.75 \mathrm{Gd}-5.15 \mathrm{Y}-0.75 \mathrm{Zr}-3.05 \mathrm{Zn}$ were selected and named as alloy $\mathrm{A}$ and $\mathrm{B}$, respectively. Their chemical compositions are listed in Table 1. First, raw material including high purity elemental $\mathrm{Mg}$ and $\mathrm{Zn}, \mathrm{Mg}-30 \mathrm{Gd}$ (wt.\%), Mg-30Y (wt.\%) and Mg-25Zr (wt.\%) with designed volume fractions were melted and casted in to two cylindrical billets, respectively. Then, these cast billets were held at $420{ }^{\circ} \mathrm{C}$ for $4 \mathrm{~h}$ isothermally and extruded into bars with a speed of $0.4 \mathrm{~mm} / \mathrm{s}$. The diameters of cylindrical billets and extruded bars were 155 and $30 \mathrm{~mm}$, respectively. The micrographs of these hot-extruded Mg-RE alloys are shown in Fig. 1. To determine the semisolid temperature ranges of these alloys, differential scanning calorimetry (DSC) analysis was conducted using a LINSEIS PT1600 high temperature differential scanning calorimeter. Based on the result of DSC analysis, the liquid fractions of two $\mathrm{Mg}-\mathrm{RE}$ alloys at different temperatures are shown in Fig. 2. The solidus and liquidus temperature of alloy A are 522 and $635^{\circ} \mathrm{C}$, respectively. Meanwhile, the solidus and liquidus temperature of alloy $\mathrm{B}$ are 503 and $595{ }^{\circ} \mathrm{C}$, respectively.

Reheating experiments and compression tests of two Mg-RE alloys were conducted on a multistage hot compression test machine under the protection of a nitrogen atmosphere. Cylindrical specimens were cut from the extruded bars. The diameter and height of these cylindrical specimens were 8 and $12 \mathrm{~mm}$, respectively. A 
cylindrical induction coil and a k-type thermocouple were used to control and measure the temperature of specimens during experiments. A pair of cylindrical ceramic dies covered by lubricated mica pads were used to fix and compress the specimen in reheating experiment and compression test, respectively. To freeze the microstructure of specimen at high temperature, specimen was cooled rapidly by cold water in the end of reheating experiment and compression test.

Table 1. Chemical compositions of Mg-RE alloys, wt $\%$.

\begin{tabular}{|l|l|l|l|l|l|}
\hline & Gd & $\mathrm{Y}$ & $\mathrm{Zn}$ & $\mathrm{Zr}$ & $\mathrm{Mg}$ \\
\hline Alloy A & 8.20 & 4.48 & 3.34 & 0.36 & Bal. \\
\hline Alloy B & 3.75 & 5.15 & 3.05 & 0.75 & Bal. \\
\hline
\end{tabular}

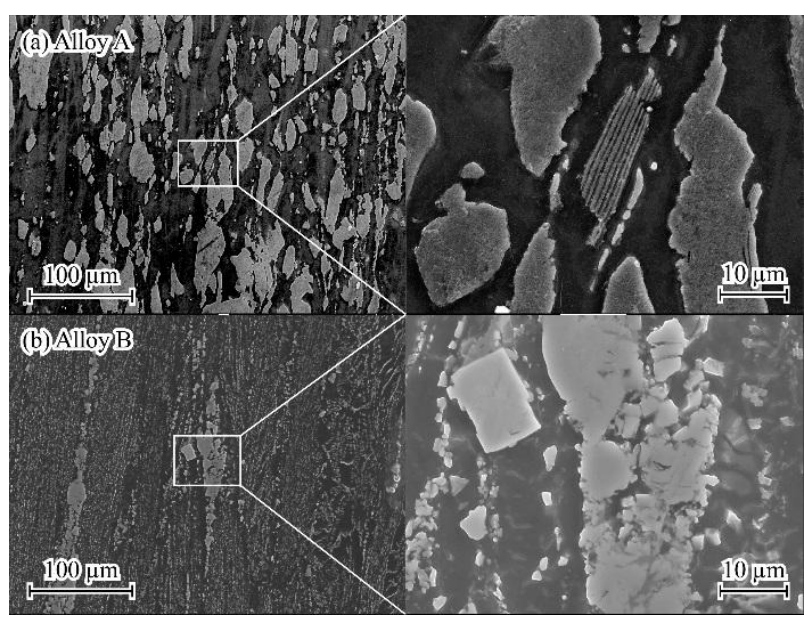

Figure 1. Micrographs of different hot-extruded Mg-RE alloys at room temperature

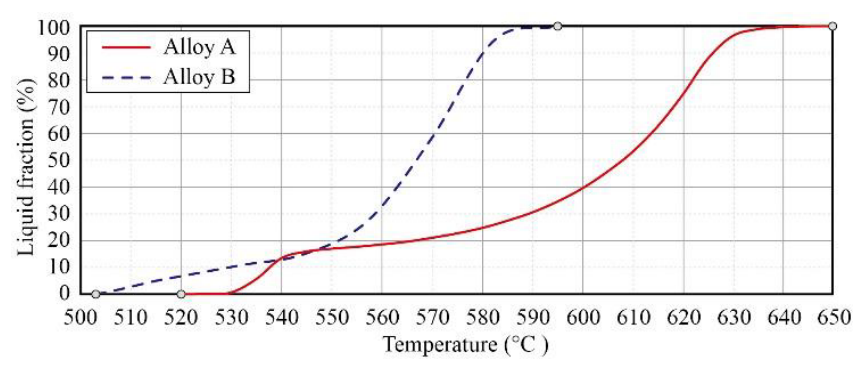

Figure 2. Liquid fractions of different hot-extruded $\mathrm{Mg}-\mathrm{RE}$ alloys at different temperatures

Different specimens processed under various experimental conditions were polished and etched in $4 \%$ nitric acid/alcohol solution. Their microstructures were observed using a field-emission scanning electron microscopy (FE-SEM) system. The qualitative and quantitative analyses of the alloying elements in the specimens were conducted using an energy-dispersive Xray spectroscopy (EDS) system. The constituent phases and their volume fractions in these specimens were analyzed by X-ray diffraction (XRD) analysis using an $\mathrm{X}$-ray diffractometer with a collimator of $\Phi 800 \mu \mathrm{m}$. Data was collected using $\mathrm{CuKa}$ radiation in the $2 \theta$ range of $20-$ $90 \mathrm{deg}$.

\section{Results and discussion}

\subsection{Starting materials}

As shown in Fig. 1a, plate-shaped and lamellar-shaped eutectic compounds were observed in alloy A. As shown in Fig. 1b, block-shaped eutectic compounds with a large size and string-shaped eutectic compounds with a small size were observed in alloy B. In both alloys A and B, eutectic compounds were distributed parallel to the extrusion direction. According to the results of XRD shown in Fig. 3, lamellar- and plate-shaped eutectic compounds in alloy A were identified as Mg12(RE, Zn) and $\mathrm{Mg} 5(\mathrm{RE}, \mathrm{Zn})$ respectively. The block- and stringshaped eutectic compounds in alloy $B$ were both identified as $\mathrm{Mg} 5(\mathrm{RE}, \mathrm{Zn})$. The inhomogeneous distribution and the morphologies of eutectic compounds in these alloys were attributed to the casting and subsequent hot extrusion processes [10]. During casting, the dendritic mode solidification of metal crystals resulted in the microsegregation of alloying elements between the interdendritic and dendritic regions. Eutectic compounds formed in the interdendritic regions with high contents of alloying elements. The dendritic structure was broken up by the subsequent hot extrusion. Thus, the eutectic compounds distributed parallel to the extrusion direction. The lamellar-shaped Mg12(RE, Zn) eutectic compounds were only observed in alloy A, owing to the different chemical compositions of these two alloys.

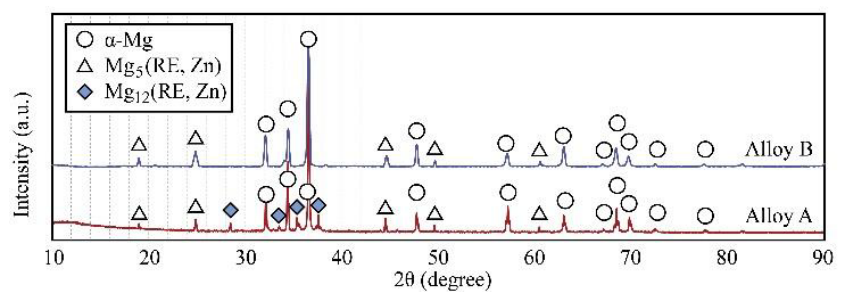

Figure 3. XRD patterns of different hot-extruded Mg-RE alloys at room temperature

\subsection{Reheating experiment}

To investigate the microstructural evolution of two $\mathrm{Mg}$ RE alloys during reheating to their semisolid temperatures, specimens were reheated to 520, 540, 560, and $580{ }^{\circ} \mathrm{C}$ with a heating rate of $20 / \mathrm{s}$ and held isothermally for $20 \mathrm{~s}$. The microstructures of specimens rapidly cooled from different temperatures are observed in longitudinal cross sections and shown in Fig. 4. Volume fractions of different eutectic compounds in different specimens cooled from different temperatures are listed in Table 2. The investigated the morphological change of $\alpha-\mathrm{Mg}$ grains during reheating quantitatively, the sizes and shape factors of $\alpha-\mathrm{Mg}$ grains in different specimens cooled from different temperatures were measured by image analysis software, the results are shown in Fig. 5. size D and shape factor F, which describes the sphericity of the solid particles, are respectively defined as following [11]: 


$$
\begin{array}{r}
D=\frac{\sum 2\left(A_{1} / \pi\right)^{0.5}}{N} \\
F=\frac{\sum 4 \pi A_{1} / P_{1}{ }^{2}}{N}
\end{array}
$$

Here Ai are the areas of the solid particles, Pi are the perimeters of the solid particles and $\mathrm{N}$ is the number of solid particles. In the case of perfectly spherical grains, $\mathrm{F}$ has a value of 1 . As shown in Fig. 5, higher reheating temperature resulted in smaller size but higher shape factor of $\alpha-\mathrm{Mg}$ grains in both alloy $\mathrm{A}$ and $\mathrm{B}$.

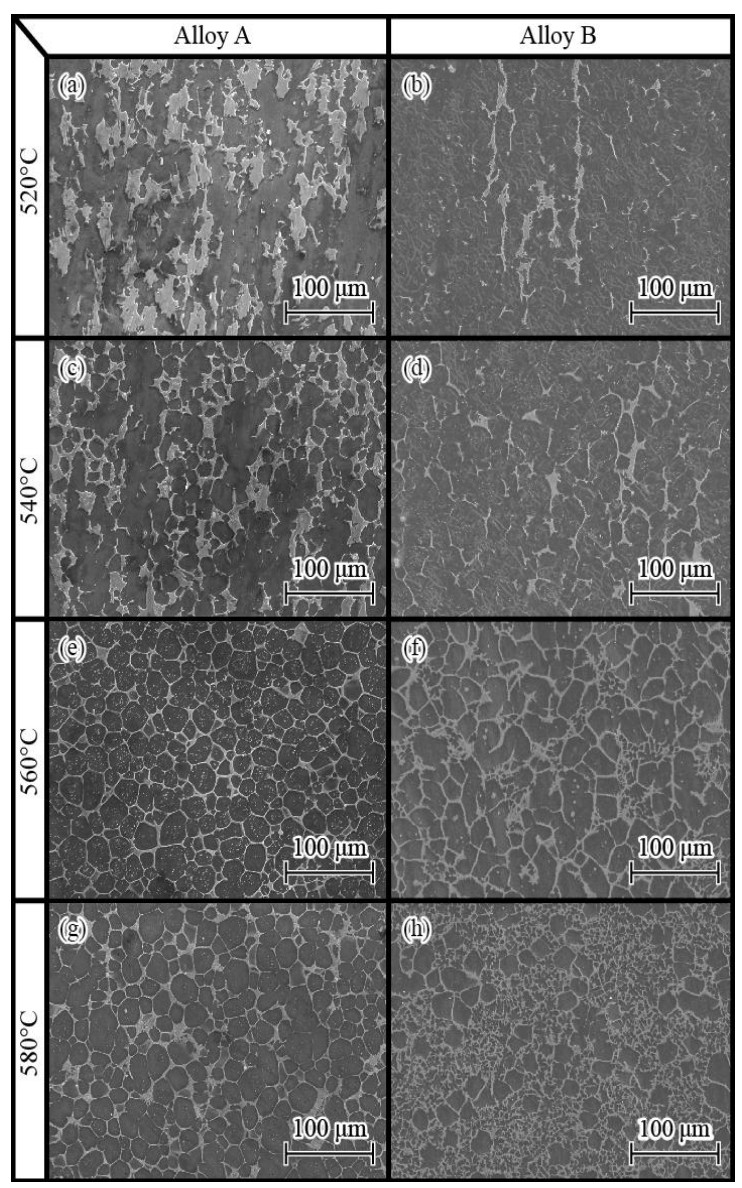

Figure 4. Micrographs of different hot-extruded Mg-RE alloys cooled from different temperatures.

As shown in Fig. 4a, the lamellar-shaped Mg12(RE, $\mathrm{Zn})$ eutectic compounds almost dissolved in the $\alpha-\mathrm{Mg}$ matrix of alloy A at $520^{\circ} \mathrm{C}$. Meanwhile, part of Mg5(RE, $\mathrm{Zn})$ eutectic compounds dissolved in the $\alpha-\mathrm{Mg}$ matrix of alloy $\mathrm{A}$ at $520^{\circ} \mathrm{C}$, as shown in Fig. 4b. Owing to the high alloying elements content in these alloys, atom positions were not enough for sufficient dissolution of eutectic compounds. The dissolution of plate-shaped Mg5(RE, Zn) eutectic compounds mainly took place on their edges and resulted in the change of their geometric morphologies. As shown in Fig. 4c, extrusion direction could be identified by the directional distribution of eutectic compounds in alloy A. According to Table 2, the volume fraction of $\mathrm{Mg} 5(\mathrm{RE}, \mathrm{Zn})$ eutectic compounds in the specimen cooled from $540{ }^{\circ} \mathrm{C}$ is lower than that of the specimen cooled from $520{ }^{\circ} \mathrm{C}$. The decreasing volume fraction of $\mathrm{Mg} 5(\mathrm{RE}, \mathrm{Zn}$ ) eutectic compounds was caused by increasing atom positions for dissolution in alloy $\mathrm{A}$ reheated to $540{ }^{\circ} \mathrm{C}$. As shown in Fig. $4 \mathrm{~d}$, some $\alpha-\mathrm{Mg}$ grains in alloy $\mathrm{B}$ were surrounded by newly formed eutectic compounds, when the reheating temperature was increased to $540{ }^{\circ} \mathrm{C}$. According to their morphology, the newly formed eutectic compounds were presumed to be (Mg, Zn)3RE. This presumption was confirmed by the increased volume fraction of $(\mathrm{Mg}, \mathrm{Zn}) 3 \mathrm{RE}$ eutectic compounds in the extruded specimen when the reheating temperature was increased from 520 to $530{ }^{\circ} \mathrm{C}$, as shown in Table 2.

Table 2. Volume fractions of different eutectic compounds in different specimens cooled from different temperatures.

\begin{tabular}{|l|l|l|l|l|}
\hline \multirow{2}{*}{} & \multirow{2}{*}{ Temperature $\left({ }^{\circ} \mathrm{C}\right)$} & \multicolumn{3}{|l|}{ Volume fraction $(\%)$} \\
\cline { 3 - 5 } & & $\mathrm{Mg}_{12}(\mathrm{RE}, \mathrm{Zn})$ & $\mathrm{Mg}_{5}(\mathrm{RE}, \mathrm{Zn})$ & $\begin{array}{l}(\mathrm{Mg}, \\
\mathrm{Zn})_{3} \mathrm{RE}\end{array}$ \\
\hline \multirow{4}{*}{$\mathrm{A}$} & Room temperature & $2.8 \pm 2.0$ & $22.4 \pm 1.0$ & 0.0 \\
\cline { 2 - 5 } & 520 & 0.0 & $20.2 \pm 1.0$ & 0.0 \\
\cline { 2 - 5 } & 540 & 0.0 & $16.8 \pm 1.0$ & $2.8 \pm 2.0$ \\
\cline { 2 - 5 } & 560 & 0.0 & $1.8 \pm 1.0$ & $12.6 \pm 2.0$ \\
\cline { 2 - 5 } & 580 & 0.0 & $2.0 \pm 1.0$ & $17.5 \pm 2.0$ \\
\hline \multirow{4}{*}{$\mathrm{B}$} & Room temperature & 0.0 & $18.4 \pm 2.0$ & 0.0 \\
\cline { 2 - 5 } & 520 & 0.0 & $4.3 \pm 1.0$ & $6.6 \pm 2.0$ \\
\cline { 2 - 5 } & 540 & 0.0 & 0.0 & $13.2 \pm 3.0$ \\
\cline { 2 - 5 } & 560 & 0.0 & 0.0 & $23.6 \pm 3.0$ \\
\cline { 2 - 5 } & 580 & 0.0 & 0.0 & $43.3 \pm 5.0$ \\
\hline
\end{tabular}

According to Fig. 2, the liquid fraction of alloys A and $\mathrm{B}$ increased to $18 \%$ and $32 \%$ at $560{ }^{\circ} \mathrm{C}$, respectively. More eutectic compounds were observed in the rapidly cooled specimens as shown in Figs. $4 \mathrm{e}$ and $4 \mathrm{f}$. It means that when the reheating temperature increased to $560{ }^{\circ} \mathrm{C}$, more partial melting occurred on grain boundaries and resulted in more liquid films in these regions. The increasing liquid phase connected and formed liquid network surrounding the discrete solid particles. The distribution of eutectic compounds in these specimens no longer exhibited any directionality. XRD patterns of alloys $\mathrm{A}$ and $\mathrm{B}$ cooled from $560{ }^{\circ} \mathrm{C}$ are shown in Fig. 6 . According to Fig. 6 and Table 2, the eutectic compound networks in these specimens were mainly composed of $(\mathrm{Mg}, \mathrm{Zn}) 3 \mathrm{RE}$. The volume fraction of $(\mathrm{Mg}, \mathrm{Zn}) 3 \mathrm{RE}$ in alloys $\mathrm{A}$ and $\mathrm{B}$ increased with the increasing reheating temperature. Moreover, when the reheating temperature increased from 540 to $560{ }^{\circ} \mathrm{C}$ the volume fraction of $\mathrm{Mg} 5(\mathrm{RE}, \mathrm{Zn})$ eutectic compounds in alloy A decreased rapidly. The decrease of $\mathrm{Mg} 5(\mathrm{RE}, \mathrm{Zn})$ eutectic compounds is estimated as a dynamic process. During reheating, $\mathrm{Mg} 5(\mathrm{RE}, \mathrm{Zn})$ kept dissolving in adjacent $\mathrm{Mg}$ grains and made the edge regions of $\mathrm{Mg}$ grains rich in alloying elements. These regions of $\mathrm{Mg}$ grains melted and resulted in increasing volume fraction of liquid phase at elevated temperature. Part of $\mathrm{Mg} 5(\mathrm{RE}, \mathrm{Zn})$ also dissolved in the neighboring liquid network simultaneously. During subsequent rapid cooling process, liquid phase mainly transformed to $\mathrm{Mg} 3(\mathrm{RE}, \mathrm{Zn}$ ) eutectic compounds and $\alpha-\mathrm{Mg}$. In compared with $\mathrm{Mg} 5(\mathrm{RE}, \mathrm{Zn}$ ), $\mathrm{Mg} 3(\mathrm{RE}, \mathrm{Zn}$ ) contains less $\mathrm{Mg}$ element but more alloying elements. More $\mathrm{Mg}$ atoms were released during reheating and subsequent cooling processes. Above description could explain why the measured volume fraction of total 
eutectic compounds in alloy A decreased rapidly when the reheating temperature increased from 540 to $560{ }^{\circ} \mathrm{C}$.
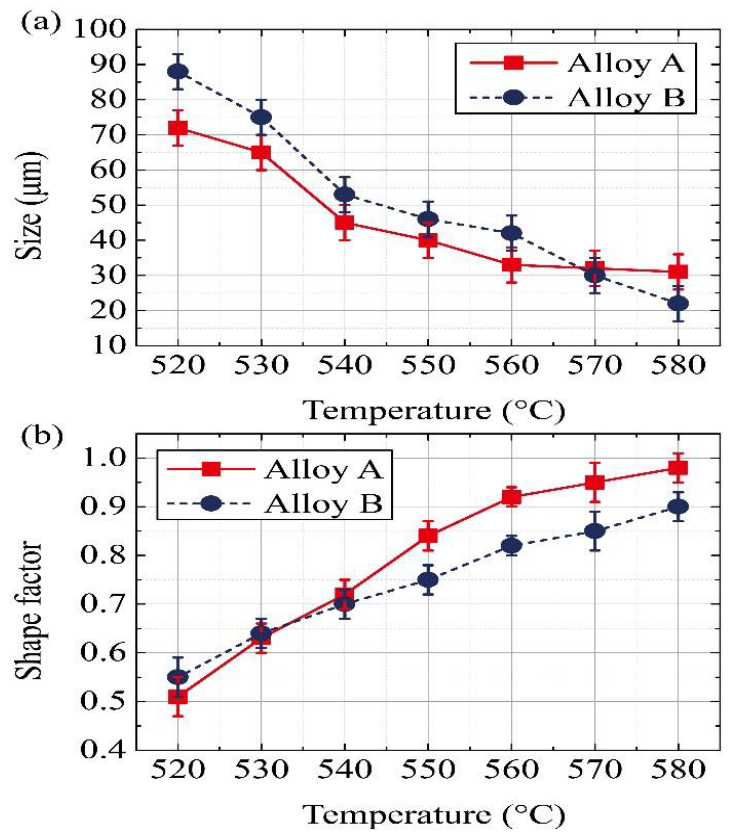

Figure 5. Sizes and shape factors of $\alpha-\mathrm{Mg}$ grains in different specimens cooled from different temperatures

When reheating temperature was increased to $580{ }^{\circ} \mathrm{C}$, the liquid fraction of alloys $\mathrm{A}$ and $\mathrm{B}$ increased to $25 \%$ and $84 \%$, respectively. Homogenous microstructures containing an equiaxed spherical $\mathrm{Mg}$ grains surrounded by uniform eutectic compound networks were observed in rapidly cooled specimen of alloy A, as shown in Fig. 4g. According to Table 2, Mg3(RE, Zn) and Mg5(RE, Zn) were the main eutectic compounds in the alloy A cooled from $580{ }^{\circ} \mathrm{C}$. Both the volume fractions of these eutectic compounds increased when the reheating temperature increased from 560 to $580{ }^{\circ} \mathrm{C}$. This phenomenon was attributed to the continuing partial melting of the specimen. During the rapid cooling, part of the liquid phase solidified as the edge regions of $\mathrm{Mg}$ grains. A systematic investigation on the partial solidification of liquid phase during cooling was done by researchers from Germany $[12,13]$, solidified parts in the grains cannot be distinguished from former solid particles by normal methods. However, the dendritic casting structures dominated in the alloy B cooled from $580{ }^{\circ} \mathrm{C}$, as shown in Fig. 4h. According to Table 2, $(\mathrm{Mg}, \mathrm{Zn}) 3 \mathrm{RE}$ with the largest volume fraction were measured in alloy B cooled from $580{ }^{\circ} \mathrm{C}$. On the basis of the description above, the illustration of microstructural evolution of alloys A and B during reheating and rapid cooling processes are illustrated as Figs .7 and 8, respectively.

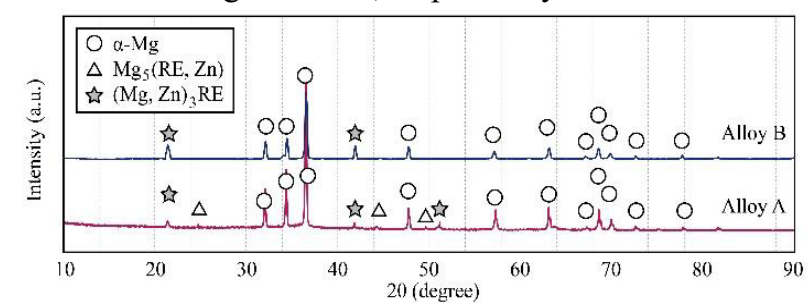

Figure 6. XRD patterns of different hot-extruded Mg-RE alloys cooled from $560{ }^{\circ} \mathrm{C}$.

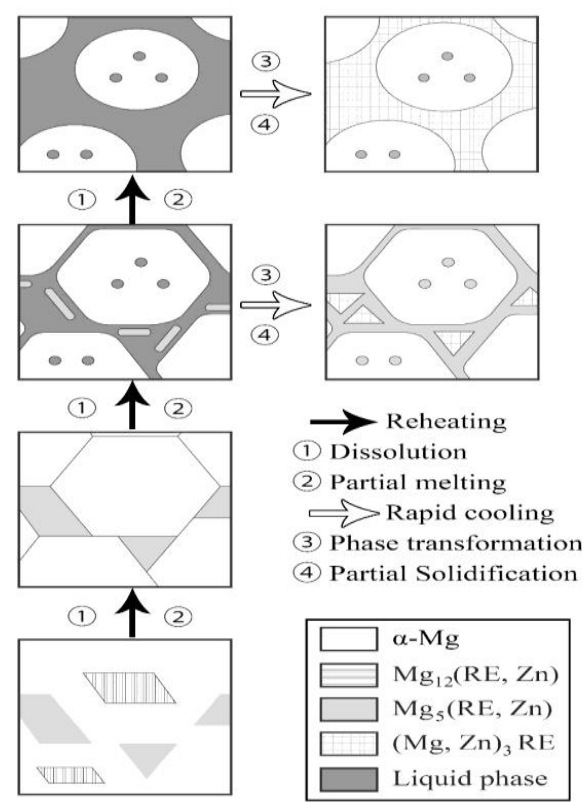

Figure 7. Illustration of microstructural evolution of alloy A during reheating and rapid cooling processes

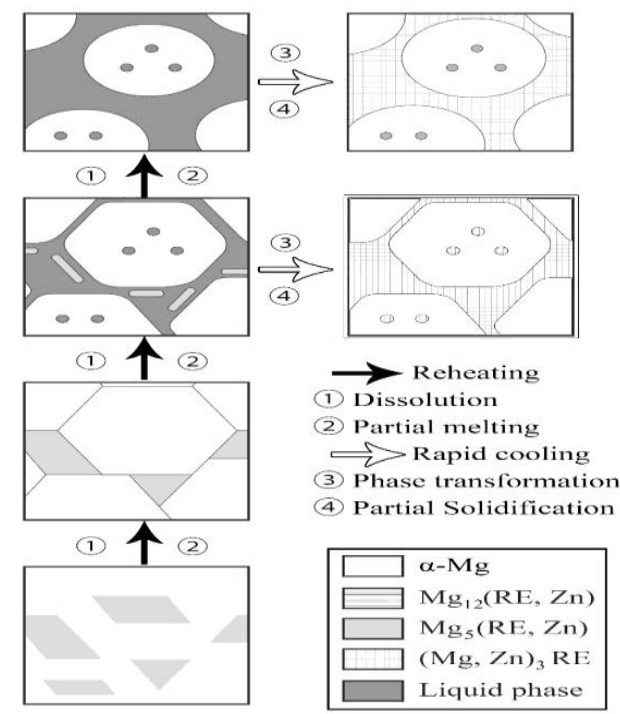

Figure 8. Illustration of microstructural evolution of alloy B during reheating and rapid cooling processes.

\subsection{Semisolid compression}

Specimens of two Mg-RE alloys were heated to 520, 530, $540,550,560,570$, and $580{ }^{\circ} \mathrm{C}$ with a heating rate of $20 / \mathrm{s}$ and compressed with a strain rate of $1 / \mathrm{s}$ to $70 \%$ height reduction after isothermal holding for $20 \mathrm{~s}$. The timeload-stroke data were recorded and calculated using following equations by a computer system.

$$
\begin{aligned}
& \sigma=\frac{F\left(H_{0}-\Delta H\right)}{\pi \cdot R^{2} \cdot H_{0}} \\
& \varepsilon=\ln \frac{H_{0}-\Delta H}{H_{0}}
\end{aligned}
$$

where $H_{0}$ and $R_{0}$ are the original height and radius of the specimen, respectively, and $F$ and $\Delta H$ are the measured 
load and stroke, respectively. Owing to the liquid fraction of alloy $\mathrm{B}$ was too high when forming temperature excessed $560{ }^{\circ} \mathrm{C}$, the measured values of the load were too low to calculate the flow stress. The calculated results for the cast and extruded specimens are shown in Fig. 9.

The thixoforming behaviors of the semisolid slurries were affected by their liquid fractions and the morphologies of the solid phases [14]. When thixocompression tests were conducted at lower semisolid temperatures, the outflow of the liquid phase with a lower volume fraction was difficult. Plastic deformation of the solid particles dominated during thixo-compression and resulted in higher values of the flow stress. As shown in Figs. 4 and 5, the semisolid slurries containing solid particles more spherical profiles and liquid phases with higher volume fraction were obtained at higher temperatures. Because liquid phase with a higher volume fractions exhibited excellent fluidity, liquid phase flowed outwards under forming load. Thus, outflow of the liquid phase and sliding and rotation of the spherical solid particles occurred during semisolid compression and resulted in lower values for the flow stress. Because the liquid fraction of alloy A was higher than that of alloy B at same temperature, lower value of flow stress was obtained in semisolid compression of alloy B at each forming temperature.

In order to express the yield strength $\left(\sigma_{y}\right)$ of a semisolid slurry with a specific solid fraction (fs) during thixoforming, following equation was employed [15].

$$
\sigma_{y}=A \exp \left(B f_{s}\right)
$$

Here, $\mathrm{A}$ and $\mathrm{B}$ are the material constants. The relationship between the yield strength and liquid fraction $\left(f_{l}\right)$ can be described by the following equation:

$$
\sigma_{y}=A \exp \left[B\left(100-f_{l}\right)\right]
$$
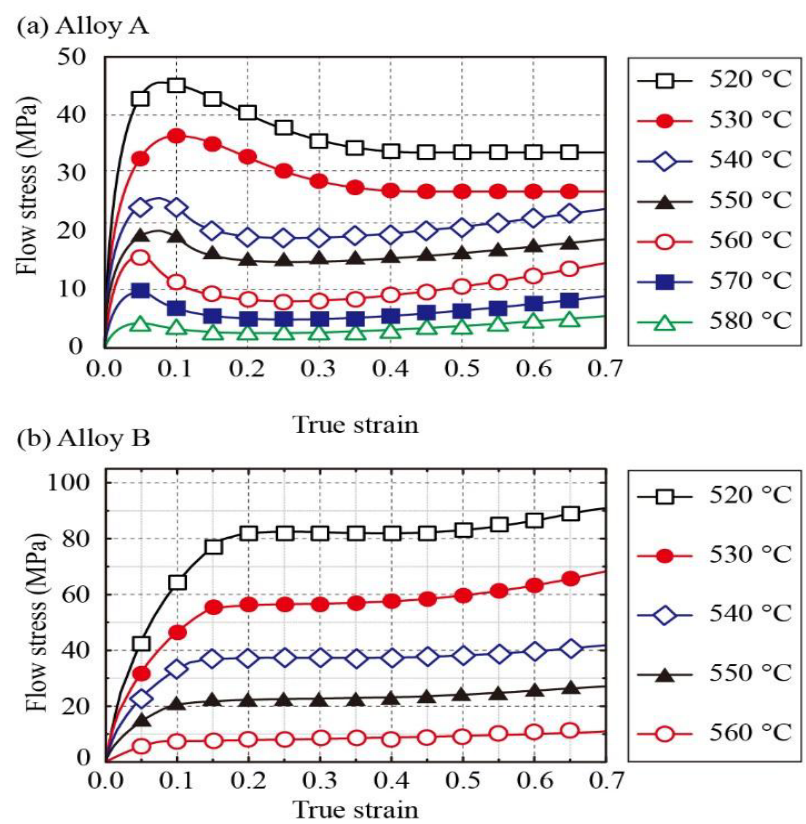

Figure 9. Flow stress-true strain curves of different hotextruded Mg-RE alloys compressed at different temperatures.
To obtain the values of $\mathrm{A}$ and $\mathrm{B}$, Equation 6 was transformed to Equation 7.

$$
\ln \sigma_{y}=\ln A+B\left(100-f_{l}\right)
$$

Based on the flow stress-true strain curves shown in Fig. 9, the values of the material constants for the two Mg-RE alloys were calculated by a linear fitting method. The yield strengths for alloys $\mathrm{A}$ and $\mathrm{B}$ in the temperature range from 520 to $580{ }^{\circ} \mathrm{C}$ are described by Equations 8 and 9 , respectively. The yield strengths obtained from the experiments and calculations are shown in Fig. 10.

$$
\begin{aligned}
\sigma_{y} & =0.03660 \exp \left[0.07213\left(100-f_{l}\right)\right] \\
\sigma_{y} & =0.02256 \exp \left[0.08686\left(100-f_{l}\right)\right]
\end{aligned}
$$

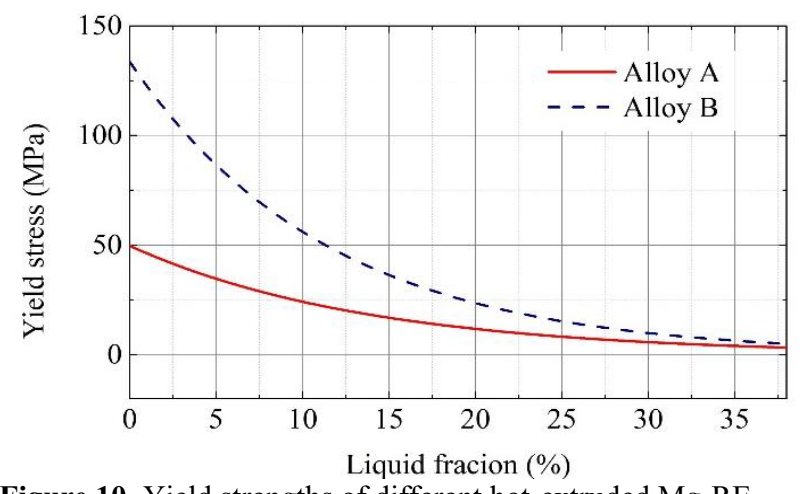

Figure 10. Yield strengths of different hot-extruded Mg-RE alloys with different liquid fractions during thixoforming

\section{Conclusion}

The results obtained in this study are concluded summarized as follows:

The partial melting behaviors of two hot-extruded Mg-RE alloys were investigated experimentally. Homogenous spherical semisolid slurries of alloys A and $\mathrm{B}$ were obtained when these alloys were reheated to $580{ }^{\circ} \mathrm{C}$ and $560{ }^{\circ} \mathrm{C}$, respectively.

Phase transformation and arrangement of alloying elements took place during reheating and subsequent cooling of two hot-extruded Mg-RE alloys. These microstructural behaviors were affected by the chemical compositions of these alloys.

The thixoforming properties of the semisolid slurries were not only affected by the liquid fraction, but also depended on the distribution and morphologies of solid particles. Semisolid slurry with higher liquid fractions and more globular solid particles exhibited better formability.

\section{Acknowledgment}

This study was financially supported by National Natural Science Foundation of China (contract No. 51605055), Chongqing Natural Science Foundation (contract No. cstc2016jcyjA1027), and Fundamental Research Funds for Central Universities (contract No.0903005203307). 


\section{References}

Online references will be linked to their original source, only if possible. To enable this linking extra care should be taken when preparing reference lists.

1. J.F. Nie, X. Gao, S.M. Zhu, Scr. Mater. 53, 1049 (2005).

2. Q. Chen, D. Shu, C. Hu, Z. Zhao, B. Yuan, Mater. Sci. Eng. A 541, 98 (2012).

3. C. Xu, M. Zheng, S. Xu, K. Wu, E. Wang, G. Fan, S. Kamado, Mater. Sci. Eng. A 643, 137 (2015).

4. S.W. Xu, M.Y. Zheng, S. Kamado, K. Wu, G.J. Wang, X.Y. Lv, Mater. Sci. Eng. A 528, 4055 (2011).

5. C. Xu, M.Y. Zheng, K. Wu, E.D. Wang, G.H. Fan, S.W. Xu, S. Kamado, X.D. Liu, G.J. Wang, X.Y. Lv, Mater. Sci. Eng. A 559, 615 (2013).

6. Y. Meng, Q. Chen, S. Sugiyama, J. Yanagimoto, J. Mater. Process. Technol. 247, 192 (2017).
7. Q. Chen, Z. Zhao, D. Shu, Z. Zhao, Mater. Sci. Eng. A 528, 3930 (2011).

8. Q. Chen, B. Yuan, G. Zhao, D. Shu, C. Hu, Z. Zhao, Z. Zhao. Mater. Sci. Eng. A 537, 25 (2012).

9. Q. Chen, B. Yuan, J. Lin, X. Xia, Z. Zhao, D. Shu. J. Alloys Compd. 584,53 (2014).

10. M.Z. Omar, E.J. Palmiere, A.A. Howe, H.V. Atkinson, P. Kapranos, Mater. Sci. Eng. A 395, 53 (2005).

11. Y. Meng, S. Sugiyama, J. Yanagimoto, J. Mater. Process. Technol. 225, 203 (2015).

12. W. Püttgen, B. Hallstedt, W. Bleck, P.J. Uggowitzer, Acta Mater. 55,1033 (2007)

13. W. Püttgen, B. Hallstedt, W. Bleck, J.F. Löffler, P.J. Uggowitzer, Acta Mater. 55, 6553 (2007).

14. J. Li, S. Sugiyama, J. Yanagimoto, Y. Chen, W. Guan, J. Mater. Process. Technol. 208,165 (2008).

15. A.A. Tseng, J. Horský, M. Raudenský, P. Kotrbácek, Mater. Design 22, 83 (2001). 